\title{
Cell, Stem cells and Regenerative Medicine
}

\section{Human and Dogs' Gingival Stem Cells are Different}

\section{Tarek El-Bialy ${ }^{1 *}$, Cezary Kucharski ${ }^{2}$, Mamdouh Farid ${ }^{3}$, Khaled Abdel Ghaffar ${ }^{4}$, Elham Fawzi ${ }^{5}$, and Ali Saleem ${ }^{3}$}

${ }^{1,2}$ University of Alberta, Department of Dentistry, Faculty of Medicine and Dentistry, Medical Graduate Orthodontic Program, Edmonton, Alberta, Canada

${ }^{3}$ Queen Medical Center, Doha, Qatar

${ }^{4}$ Professor and Chair of Oral Medicine and Periodontology, Faculty of Dentistry, Ain- Shams University, Cairo, Egypt

${ }^{5}$ Faculty of Oral and Dental Medicine, Cairo University/Egypt

"Corresponding author: Dr Tarek El-Bialy, BDS, M.Sc, PhD, FRDC, EMBA, Department of Dentistry and Biomedical Engineering, Faculty of Medicine and Dentistry, 7-020 D, 7th Floor, Katz Group Centre for Pharmacy and Health Research, University of Alberta, Edmonton, Alberta, Canada, Tel: 1-780-492-2751; Fax: 1-780-492-1624; E-mail: telbialy@ualberta.ca
Received date: 24 June 2015; Accepted date: 15 July 2015; Published date: 22 July 2015.

Citation: El-Bialy T, Kucharski C, Farid M, Ghaffar KA, Fawzi E, et al. (2015) Human and Dogs' Gingival Stem Cells are Different. Cell Stem Cells Regen Med 1(1): doi http://dx.doi.org/10.16966/2472-6990.103

Copyright: (c) 2015 El-Bialy T, et al. This is an open-access article distributed under the terms of the Creative Commons Attribution License, which permits unrestricted use, distribution, and reproduction in any medium, provided the original author and source are credited.

\begin{abstract}
Objective:

To test the hypothesis that human and canine gingival mesenchymal stem cells have similar stem cell characteristics and that low intensity pulsed ultrasound (LIPUS) enhances these characteristics.

Method:

Human and canine gingival mesenchymal cells (HGMCs and CGMCs) were isolated, expanded then each population was divided into two subgroups, one subgroup was treated by LIPUS for 20 minutes and the other subgroup was served as control. LIPUS was applied using an ultrasound device that produces spatial average temporal average intensity of $30 \mathrm{~mW} / \mathrm{cm}^{2}$. Pulses are $1.5 \mathrm{MHz}$ and pulse repetition frequency is $1 \mathrm{kHz}$. 24 hours later, cells were collected and evaluated by flowcytometry for stem cell markers CD11b; CD14; CD34; CD45; CD73; CD90 and CD105. Also, cells were also cultured in regular Alpha DMEM or osteogenic media. Alkaline phostphatase, DNA and MTT analyses were performed.

Result:

Flow cytometry analysis showed that control and LIPUS treated canine CGMCs were partially positive only for CD90 and negative for the rest of the stem cell markers. However CD90 expression was decreased (5\%) by LIPUS compared to non LIPUS treated CGMCs. On the other hand, HGMCs showed higher CD73, CD90, and CD105 expression than CGMCs. In addition, LIPUS enhanced these stem cell markers expression in HGMCs. MTT was increased in HGMCs in regular or osteogenic medium, while it was increased only in CGMCs in osteogenic medium. ALP was significantly increased in HGMCs when cultured in osteogenic medium with or without LIPUS application. No difference between CGMCs and HGMCs with respect to DNA expression.
\end{abstract}

\section{Conclusion:}

HGMCs show more multipotent potential with or without LIPUS application compared to CGMCs, especially when they were cultured in osteogenic medium.

Keywords: Gingival stem cells; Low intensity pulsed ultrasound (LIPUS); Beagle dogs; Human

\section{Introduction}

Research in dentofacial area has been focused on stem cell therapy and tissue engineering in the past few decades. Stem cell therapy and/or tissue engineering requires adequate number of stem cells to either treat defective tissue or organ or to be used to tissue engineer lost or defective organ. One of the challenges in either stem cell therapy and/or tissue engineering is the availability of stem cell resources. Gingival stem cells have been investigated recently as an alternative source compared to bone marrow mesenchymal cells in craniofacial tissue engineering [1]. Gingival stem cells has received a great attention in recent years compared to other sources of stem cells for craniofacial regeneration using cell therapy or tissue engineering due to its availability and no much invasiveness in its isolation techniques [1-5]. Previous research has shown that mechanical stress induces biological effects in different types of cells [6,7]. Low intensity pulsed ultrasound (LIPUS), a form of mechanical stress, has been extensively studied recently with respect of their regenerative potential in human craniofacial area. LIPUS has been shown to have anabolic effect on different types of cells including cementobalsts, periodontal ligament cells, gingival cells, skin fibroblasts, muscle cells, chondrocytes, synovial cells, periosteal cells, bone marrow stem cells and human umbilical cordderived mesenchymal stem cells [2-4,8-22]. Up till now, there is no report on the effect of ultrasound on Beagle dog's gingival stem cell. Translational research assumes that experiment outcomes in animals are reflected in human when similar treatment modality is experienced with human patients. In reality, there are many differences in treatment responses between animals and in human. Therefore, it is not usually expected that a positive treatment outcome in animals would produce similar effect in human. For this particular reason. The aim of this study was to compare the effect of LIPUS on canine (Beagle dogs) and human gingival stem cells. 


\section{Materials and Methods}

\section{Beagle dogs and human gingival cells}

Gingival mesenchymal stem cells were isolated from 7 beagle dogs (CGMCs) and also other 10 human patients (HGMCs). The isolation of CGMCs from beagle dogs' gingiva was performed as part of a previously approved animal care protocol at the University of Alberta, Edmonton, Canada. Also, the isolation of gingival stem cells from human gingival tissues was performed in accordance with the approved human ethics protocol at the University of Alberta. The protocol of isolating gingival mesenchymal stem cells was previously reported $[2,6]$. Cells were either treated with MEM Alpha Medium (Alpha MEM: $450 \mathrm{ml}$, Fetal Bovine Serum (FBS): $50 \mathrm{ml}$, Penicillin/Streptomycin: $5 \mathrm{ml}$, HEPES: $10 \mathrm{mmol}$ ) or osteogenic medium (DMEM: $450 \mathrm{ml}$, Fetal Bovine Serum (FBS): 50 $\mathrm{ml}$, Dexamethasone: $10 \mathrm{nM}$, B-Glycerophosphate: $10 \mathrm{mmol}$, Ascorbic Acid: $50 \mathrm{mg} / \mathrm{l}$, HEPES: $10 \mathrm{mmol}$, Penicillin/Streptomycin: $5 \mathrm{ml}$ ) and were treated with either LIPUS or no LIPUS. Cells were incubated at $37^{\circ} \mathrm{C}$ and $5 \% \mathrm{CO}_{2}$ then expanded for 10 days till $\mathrm{P} 4$ and media was changed every 3-4 days. All assays were performed three times in three different wells for a total of 9 readings in each assay. Comparison between groups was performed using one-way ANOVA with Turkey's post hoc using SPSS (Version 22) statistical package (SPSS, Chicago, IL, USA).

\section{LIPUS treatment}

After cell expansion, cells were seeded on 12-well plates, and, a day after seeding, treated by LIPUS for 20 minutes for one day. LIPUS was applied using a custom-made LIPUS device (SmileSonica Inc., Edmonton, Canada) that produces pulses of $1.5 \mathrm{MHz}$ with pulse repetition frequency of $1 \mathrm{KHz}$ and intensity of $30 \mathrm{~mW} / \mathrm{cm}^{2}$ of the transducer surface area. LIPUS was applied to the cell culture plates from below and inside the incubator using ultrasound gel (SmileSonica Inc., Edmonton, Canada).

\section{Cell viability}

The MTT (3-(4,5-dimethylthiazol-2-yl)-2,5-diphenyltetrazolium bromide) assay was used to evaluate cell viability as previously described [2,21]. Briefly, $100 \mathrm{ml}$ of MTT solution (dissolved in Hank's Balanced Salt Solution (HBSS) at $5 \mathrm{mg} / \mathrm{ml}$ ) was added into each well containing cells with $0.5 \mathrm{ml}$ basic medium (Dulbecco's Modified Eagle Medium (DMEM), $100 \mathrm{U} / \mathrm{ml}$ penicillin, and $100 \mathrm{mg} / \mathrm{ml}$ streptomycin (Invitrogen, Carlsbad, CA, USA).

After 2 hours, the medium was replaced with $2 \mathrm{ml}$ of dimethylsulfoxide to dissolve the formed MTT formazan crystals. Then, the absorbance was quantified at $570 \mathrm{~nm}$ and was used to evaluate cell viability [2,23].

\section{Immunophenotyping using flow cytometry}

In order to identify cell surface markers of HGMCs or CGMCs, FITC-labelled antibodies, namely CD11b, CD14, CD34, CD45, CD73, $\mathrm{CD} 90$ and CD105 were used to detect the presence of the corresponding binding sites by flow cytometry analysis [24]. CD14 and CD11b are prominently expressed on monocytes and macrophages, the most likely cells to be found in an MSC culture, CD34-R-phycoerythrin (it marks primitive hematopoietic progenitors and endothelial cells), CD45phycoerythrin (is a pan-leukocyte marker), CD73 (known as ecto 5' nucleotidase and originally recognized by the MAb SH3 and SH4), CD90 (Thy1) R-phycoerythrin and CD 105 (known as endoglin and originally recognized by the MAb SH2) [24] (R-PE, BD Bioscience, Mississauga, $\mathrm{ON}$, Canada). FITC-conjugated Isotype-mouse IgGa1 and PE-conjugated Isotype-mouse IgGk1 served as secondary antibodies (control antibodies). 10,000 labeled cells were acquired and analyzed using a FACS can flow cytometer running Cell Quest software (Becton Dickinson, Mississauga, ON, Canada).

\section{ALP/DNA assays}

ALP is known as a membrane bound enzyme that has the highest activity before the beginning of mineralization as well as a biochemical marker for osteogenic /osteoblast cell differentiation [2,21,22]. Cells were washed with HBSS and lysed with ALP buffer (0.5 M 2-amino-2-methylpropan-1ol and $0.1 \%(\mathrm{v} / \mathrm{v})$ Triton X-100; $\mathrm{pH}$ 10.5). One hour after the lysis, $100 \mathrm{ml}$ of lysed solution (in duplicate) was added to 96-well plates, and $100 \mathrm{ml}$ of 2 $\mathrm{mg} / \mathrm{ml}$ ALP substrate p-nitrophenol phosphate (pNPP) (Sigma, St.Louis, $\mathrm{MO}$ ) was added to lysed cells to give a final concentration of $1 \mathrm{mg} / \mathrm{ml}$ pNPP. The absorbance was measured at $405 \mathrm{~nm}$ at periodic intervals for up to $20 \mathrm{~min}$. The ALP activity was reported in terms of the $\mathrm{p}$-NPP product formed ( $\mathrm{p}$-nitrophenol; in $\mathrm{mmol} / \mathrm{min} / \mathrm{ml}$ ), and normalized with the DNA content to obtain a specific ALP activity (ALP/DNA). The DNA content of the lysates was determined using CyQUANT DNA kit (Molecular Probes, Eugene, Oregon, USA) following the manufacturer's instructions. DNA standard provided with the CyQUANT kit was used for calibration and to measure DNA concentrations in each group of cells. DNA was quantified using a fluorescence plate reader (ELx 800 Universal Plate Reader made by BioTek Instruments Inc. in Winooski,VT,USA) (excitation at $480 \mathrm{~nm}$; emission at $527 \mathrm{~nm}$ )

\section{Results}

\section{Effect of LIPUS on cell viability}

The effect of LIPUS on both CGMCs and HGMCs viability was assessed by the MTT assay. MTT absorbance in both CGMCs and HGMCs was statistically increased by LIPUS in osteogenic medium $(\mathrm{P}<0.005)$. However, LIPUS did not show any difference in MTT absorbance when CGMCs were treated with Alpha medium. In contrast, MTT absorbance by HGMSCs was increased significantly by LIPUS $(\mathrm{P}=0.031)$ (Figures $1 \mathrm{~A}$ and $\mathrm{B}$ ). HGMCs showed statistically significant higher MTT values in all groups compared to CGMCs (Figure 1C).

\section{Effect of LIPUS on cell markers expression}

In contrast to HGMCs that showed similar behaviour to stem cells regarding percent gated labelled cells with stem cells markers (being +ve to CD73, CD 90, CD 105, -ve to CD11b, CD14, CD34 and CD45), CGMCs did not show +ve expression of CD73 or CD105. However, CGMSCs were similar to HGMSCs in all other markers expression. In CGMCs (Figures 2A and 2B), LIPUS did not affect the -ve response to CD11b, CD14, CD34, CD45, CD73 or CD105. However, LIPUS decreased mean percent gated CGMCs labelled with CD90 by $5 \%(\mathrm{P}<0.05)$. On the other hand, LIPUS increased mean gated HGMCs labelled with CD73 $(\mathrm{P}<0.005)$, $\mathrm{CD} 90$ and $\mathrm{CD} 105(\mathrm{P}<0.001)$ (Figure $2 \mathrm{~B})$.

\section{Effect of LIPUS on ALP/DNA}

Comparison between HGMCs and CGMCs ALP, DNA and ALP/DNA ratio showed significant decreased in all parameters in CGMCs compared

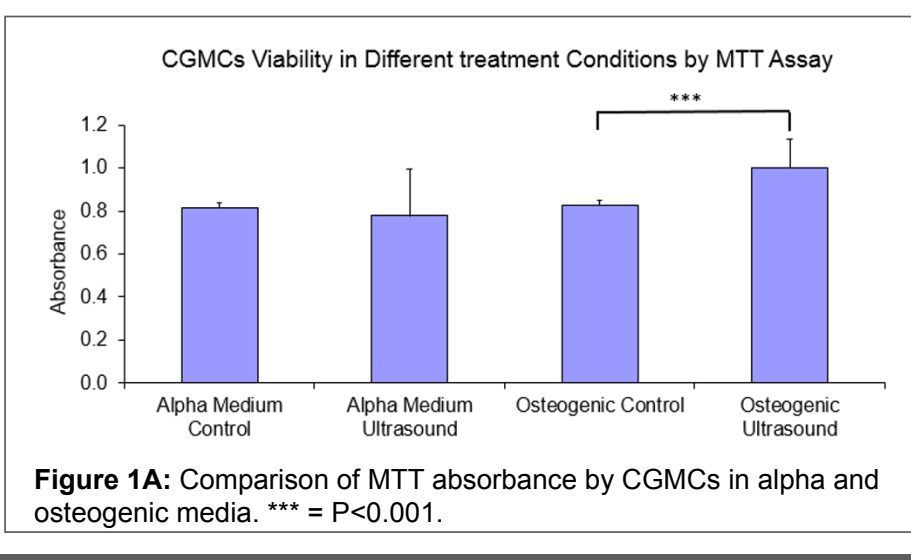


Open Access

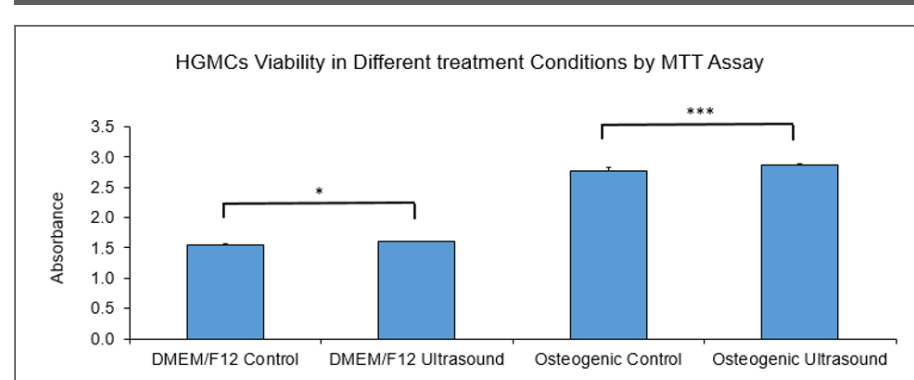

Figure 1B: Comparison of MTT absorbance by CGMCs in alpha and osteogenic media. ${ }^{* * *}=\mathrm{P}<0.001$.

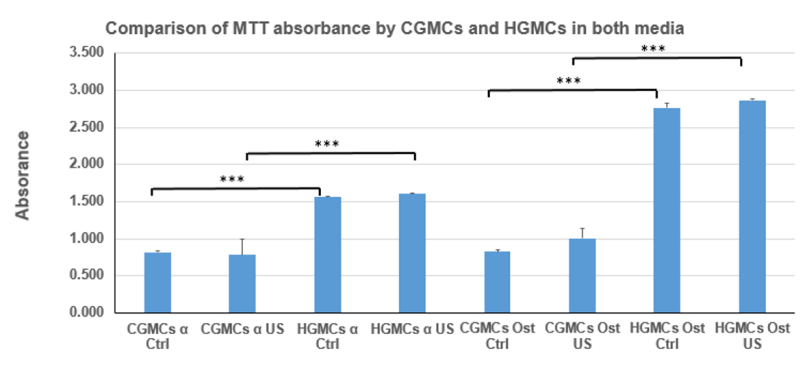

Figure 1C: Comparison of MTT absorbance between CGMCs and HGMCs in alpha and osteogenic media. ${ }^{* *}=\mathrm{P}<0.001$.

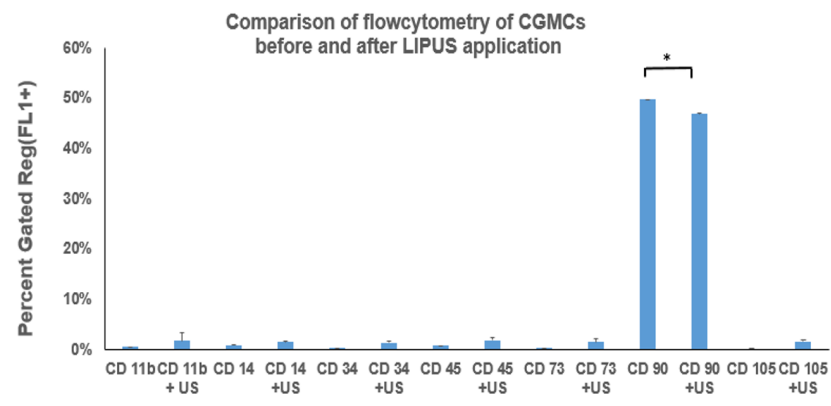

Figure 2A: Comparison of flowcytometry of HGMCs before and after LIPUS application. ${ }^{* *}=\mathrm{P}<0.005,{ }^{* * *}=\mathrm{P}<0.001$.

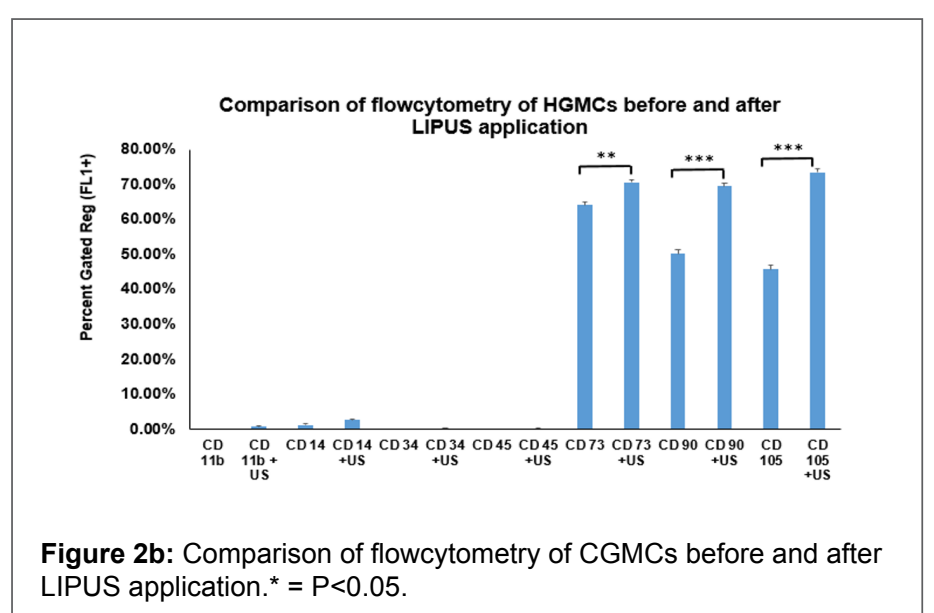

to HGMCs (Figures 3A, 3B and 3C). LIPUS decreased ALP, and ALP/ DNA ratio in HGMCs in osteogenic medium, the difference was not significant (Figures 3A and 3C). Also, LIPUS did not change ALP, DNA concentrations in CGMCs either in alpha or osteogenic media (Figures $3 \mathrm{~A}$ and $3 \mathrm{~B}$ ). Although LIPUS increased ALP/DNA ratio in CGMCs, this increase was not statistically significant (Figure 3C).

\section{Discussion}

Although it has been hypothesized that human gingival fibroblasts may be used for cell therapy and tissue engineering, it would be logical to study the cell surface markers of these cells in order to consider them as

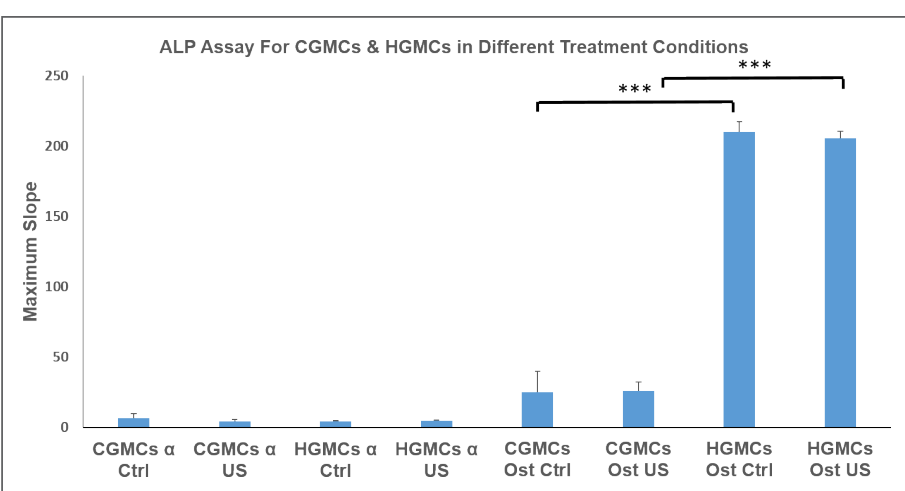

Figure 3A: Comparison of ALP assay between CGMCs and HGMCs in alpha and osteogenic media, before and after LIPUS application. $* * *=P<0.001$.

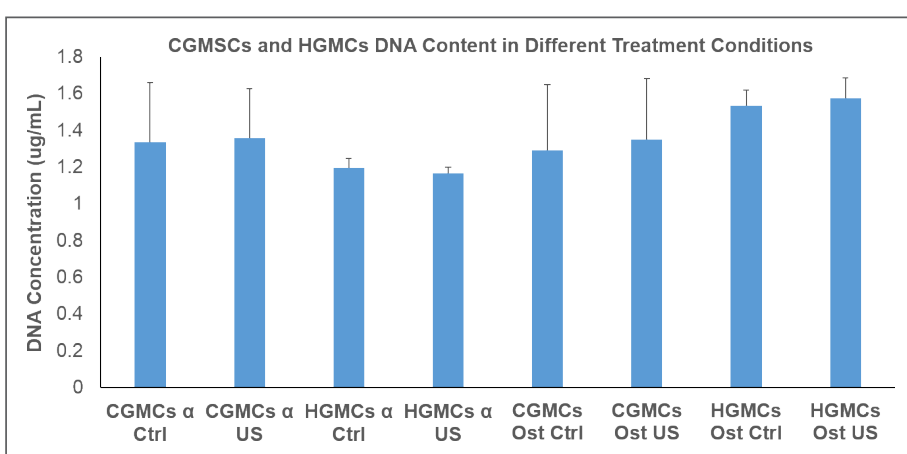

Figure 3B: Comparison of DNA assay between CGMCs and HGMCs in alpha and osteogenic media, before and after LIPUS application. $* * *=P<0.001$.

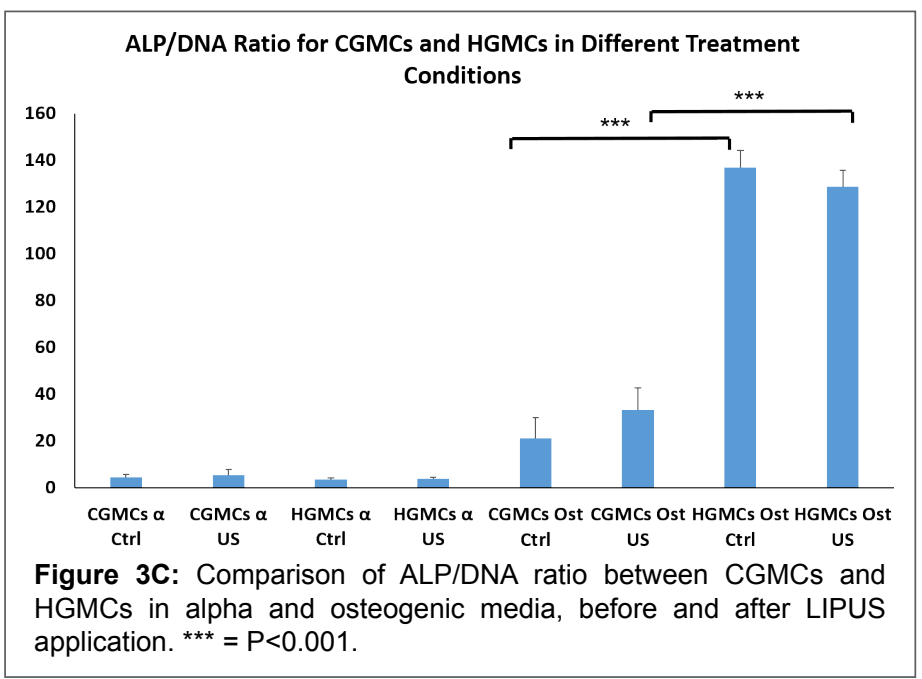

Citation: El-Bialy T, Kucharski C, Farid M, Ghaffar KA, Fawzi E, et al. (2015) Human and Dogs' Gingival Stem Cells are Different. Cell Stem Cells Regen Med 1(1): doi http://dx.doi.org/10.16966/2472-6990.103 
mesenchymal stem cells. Although previous report has shown that these cells possess some stem cell surface markers [4], these markers need to be studied more in order to confirm or otherwise discard classifying them as potential stem cells. Previous studies have shown that LIPUS has anabolic effects on human gingival fibroblast cells [2]. However, it is not known if LIPUS may or may not change these stem cell surface markers in CGMCs and HGMCs. Hence, it was our study aim to test the effect of LIPUS on HGMCs. Also, in translational research, higher animals like beagle dogs are considered as an ideal animal model for preclinical experiments. Hence, it was also important to know if CGMCs possess stem cell markers or not and is so, what would be the effect of LIPUS on these stem cell surface markers. Our study evaluated for the first time the mesenchymal stem cell markers in CGMCs and the effect of LIPUS application on these markers as well as cell viability (as evaluated by MTT) and ALP, DNA activities/concentration. Cell viability assay showed that LIPUS increased MTT absorbance in both HGMCs and CGMCs. This reflects that LIPUS did not show any deleterious effect on either cell types. This is in agreement with previous studies [2,11-15,19,26,27]. Our study showed that beagle dogs' gingival mesenchymal cells lack the expression of CD73 and CD 105. Previous position paper reported that in order to identify cells as mesenchymal stromal cells and have pluripotent characteristics, these cells must be expressing CD73, CD90 and CD105 more that $95 \%$. The lack of expression of CD73, CD105 by CGMSCs suggest that CGMCs cells cannot be identified or considered as potential stem cells as they fail to have these important criteria. In addition, CGMCs expression of CD 90 was $50 \%$ without LIPUS and $45 \%$ with LIPUS. Regardless the decreased CD90 expression by LIPUS in CGMCs, these cells at the current time may not be considered as stem cells. Also, HGMCs, although showed expression of CD73, CD90 and CD105, these markers expression in our study was lower than 95\%. Although LIPUS increased CD73, CD90 and CD105 expression, one LIPUS application did not increase the expression of these markers to the $95 \%$ level that can make these cells considered as stem cells. Future studies may be aimed at changing LIPUS parameters in order to increase the expression of these markers to the $95 \%$ level. It is to be noted that previous study showed an anabolic effect of LIPUS on human gingival fibroblasts, this anabolic effect was noted mainly after 3-4 weeks [2]. In our study, LIPUS application was for one time only based on other previous studies that applied LIPUS to different cells for one application $[14,26,27]$. Future studies may evaluate these effects on longer effect on both types of cells. Our results also showed no effect of ALP, DNA or ALP/ DNA ratio. This is in agreement with previous studies during the first week of their studies $[2,13]$. Future studies may be conducted to evaluate these effects on long term basis (1,2,3 and 4 weeks) with different LIPUS application times (5,10,15 and 20 minutes).

\section{Conclusion}

For short term application, LIPUS enhanced cell viability of HGMCs in both regular and osteogenic medium, and CGMCs in osteogenic medium only. LIPUS showed increased in human stem cell markers of HGMSCs, while LIPUS decreased expression of the only positive stem cell marker of GMCs (CD90). CGMCs have lower osteogenic differentiation potential than HGMCs.

\section{Acknowledgement}

This research is funded by Qatar National Research Fund, \# NPRP09557-3-144.

\section{References}

1. Ivanovski S, Li H, Haase HR, Bartold PM (2001) Expression of bone associated macromolecules by gingival and periodontal ligament fibroblasts. J Periodontal Res 36:131-141.

2. Mostafa NZ, Uludağ H, Dederich DN, Doschak MR, El-Bialy TH (2009)
Anabolic effects of low-intensity pulsed ultrasound on human gingival fibroblasts. Arch Oral Biol 54: 743-748.

3. Shiraishi R, Masaki C, Toshinaga A, Okinaga T, Nishihara T, et al. (2011) The effects of low-intensity pulsed ultrasound exposure on gingival cells. J Periodontol 82: 1498-1503.

4. El-Bialy T, Alhadlaq A, Wong B, Kucharski C (2014) Ultrasound effect on neural differentiation of gingival stem/progenitor cells. Ann Biomed Eng 42: 1406-1412.

5. Mostafa NZ, Uludağ $H$, Varkey M, Dederich DN, Doschak MR, et al. (2011) In vitro osteogenic induction of human gingival fibroblasts for bone regeneration. Open Dent J 5: 139-145.

6. Matsuda N, Yokoyama K, Takeshita S, Watanabe M (1998) Role of epidermal growth factor and its receptor in mechanical stress-induced differentiation of human periodontal ligament cells in vitro. Arch Oral Biol 43: 987-997.

7. Cowan KJ, Storey KB (2003) Mitogen-activated protein kinases: new signaling pathways functioning in cellular responses to environmental stress. J Exp Biol 206: 1107-1115.

8. Harle J, Salih V, Mayia F, Knowles JC, Olsen I (2001) Effects of ultrasound on the growth and function of bone and periodontal ligament cells in vitro. Ultrasound Med Biol 27: 579-586.

9. El-Bialy T, Alhadlaq A, Lam B, (2012) Effect of therapeutic ultrasound on human periodontal ligament cells for dental and periodontal tissue engineering. Open Dent J 6: 235-239.

10. Saito M, Fujii K, Tanaka T, Soshi S (2004) Effect of low and high intensity pulsed ultrasound on collagen post-translational modifications in MC3T3-E1 osteoblasts. Calcif Tissue Int 75: 384-395.

11. Zhou S, Schmelz A, Seufferlein T, Li Y, Zhao J, et al. (2004) Molecular mechanisms of low intensity pulsed ultrasound in human skin fibroblasts. J Biol Chem 279: 54463-54469.

12. Dalla-Bona DA, Tanaka E, Oka H, Yamano E, Kawai N, et al. (2006) Effects of ultrasound on cementoblast metabolism in vitro. Ultrasound Med Biol 32: 943-948.

13. Dalla-Bona DA, Tanaka E, Inubushi T, Oka H, Ohta A, et al. (2008) Cultured cementoblast stimulation by low- and high- intensity ultrasound. Arch Oral Biol 53: 318-323.

14. Inubushi T, Tanaka E, Rego EB, Kitagawa M, Kawazoe A, et al. (2008) Effects of ultrasound on the proliferation and differentiation of cementoblast lineage cells. J Periodontol 79: 1984-1990.

15. Nakamura T, Fujihara S, Katsura T, Yamamoto $K$, Inubushi $T$, et al. (2010) Effects of low-intensity pulsed ultrasound on the expression and activity of hyaluronic synthase and hyaluronidase in IL-1 $\beta$-stimulated synovial cells. Ann Biomed Eng 38: 3363-3370.

16. Rego EB, Inubushi T, Kawazoe A, Tanimoto K, Miyauchi M, et al. (2010) Ultrasound stimulation induces PGE2 synthesis promoting cementoblastic differentiation through EP2/EP4 receptor pathway. Ultrasound Med Biol 36: 907-915.

17. Nagata K, Nakamura T, Fujihara S, Tanaka E (2013) Ultrasound modulates the inflammatory response and promotes muscle regeneration in injured muscles. Ann Biomed Eng 41: 1095-1105.

18. Iwabuchi $Y$, Tanimoto K, Tanne $Y$, Inubushi T, Kamiya T, et al. (2014) Effects of low-intensity pulsed ultrasound on the expression of cyclooxygenase-2 in mandibular condylar chondrocytes. J Oral Facial Pain Headache 28: 261-268.

19. Lim K, Kim J, Seonwoo H, Park SH, Choung PH, et al. (2013) In vitro effects of low-intensity pulsed ultrasound stimulation on the osteogenic differentiation of human alveolar bone-derived mesenchymal stem cells for tooth tissue engineering. Biomed Res Int 2013: 269724.

20. Hu B, Zhang Y, Zhou J, Li J, Deng F, et al. (2014) Low-intensity pulsed ultrasound stimulation facilitates osteogenic differentiation of human periodontal ligament cells. PLoS One 9: e95168. 
21. Leung KS, Cheung WH, Zhang C, Lee KM, Lo HK (2004) Low intensity pulsed ultrasound stimulates osteogenic activity of human periosteal cells. Clin Orthop Relat Res 418: 253-259.

22. Yoon JH, Roh EY, Shin S, Jung NH, Song EY, et al. (2009) Introducing pulsed low-intensity ultrasound to culturing human umbilical cordderived mesenchymal stem cells. Biotechnol Lett 31: 329-335.

23. Issa Y, Brunton P, Waters CM, Watts DC (2008) Cytotoxicity of metal ions to human oligodendroglial cells and human gingival fibroblasts assessed by mitochondrial dehydrogenase activity. Dent Mater 24: 281-287.

24. Dominici M, Le Blanc K, Mueller I, Slaper-Cortenbach I, Marini F, et al.
(2006) Minimal criteria for defining multipotent mesenchymal stromal cells. The International Society for Cellular Therapy position statement. Cytotherapy 8: 315-317.

25. Anderson HC (1989) Mechanism of mineral formation in bone. Lab Invest 60: 320-330.

26. Scheven BA, Man J, Millard JL, Cooper PR, Lea SC, et al. (2009) VEGF and odontoblast-like cells: stimulation by low frequency ultrasound. Arch Oral Biol 54:185-191.

27. Al-Daghreer S, Doschak M, Sloane AJ, Major PW, Heo G, et al. (2013) Short-term effect of Low Intensity Pulsed Ultrasound on an ex-vivo 3-D tooth culture. Ultrasound Med Biol 39: 1066-74. 